\title{
Functional differences between two morphologically distinct cell subpopulations within a human colorectal carcinoma cell line
}

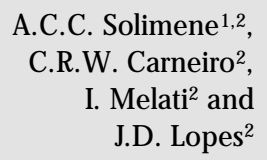

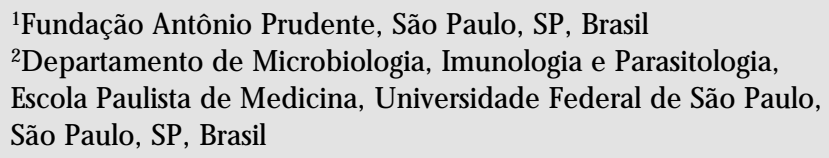

\section{Correspondence \\ C.R.W. Carneiro \\ Departamento de Microbiologia, \\ Imunologia e Parasitologia \\ EPM, UNIFESP \\ Rua Botucatu, 862, 4ำ andar \\ 04023-900 São Paulo, SP \\ Brasil \\ Fax: +55-11-572-3328 \\ E-mail: crwcarneiro@ ecb.epm.br \\ A.C.C. Solimene was the recipient of a CAPES fellowship (No. DS 00073/ \\ 97-0). Publication supported by \\ FAPESP.}

Received June 14, 2000

Accepted February 13, 2001

\section{Abstract}

The LISP-I human colorectal adenocarcinoma cell line was isolated from a hepatic metastasis at the Ludwig Institute, São Paulo, SP, Brazil. The objective of the present study was to isolate morphologically different subpopulations within the LISP-I cell line, and characterize some of their behavioral aspects such as adhesion to and migration towards extracellular matrix components, expression of intercellular adhesion molecules and tumorigenicity in vitro. Once isolated, the subpopulations were submitted to adhesion and migration assays on laminin and fibronectin (crucial proteins to invasion and metastasis), as well as to anchorage-independent growth. Two morphologically different subpopulations were isolated: LISP-A10 and LISP-E11. LISP-A10 presents a differentiated epithelial pattern, and LISP-E11 is fibroblastoid, suggesting a poorly differentiated pattern. LISP-A10 expressed the two intercellular adhesion molecules tested, carcinoembryonic antigen (CEA) and desmoglein, while LISPE11 expressed only low amounts of CEA. On the other hand, adhesion to laminin and fibronectin as well as migration towards these extracellular matrix proteins were higher in LISP-E11, as expected from its poorly differentiated phenotype. Both subpopulations showed anchorage-independent growth on a semi-solid substrate. These results raise the possibility that the heterogeneity found in the LISP-I cell line, which might have contributed to its ability to metastasize, was due to at least two different subpopulations herein identified.

\section{Introduction}

Colorectal neoplasia is the second main cause of death by cancer in developed countries (1). In Brazil, it occupies fifth place among the most common forms of cancer, being responsible for an estimated death rate of $5.05 \%$ of all cancer patients for 1999 (2). Most of the knowledge about the genetic
Key words

- Carcinoembryonic antigen

- CEA

- Colorectal carcinoma cell line

- Laminin

- Fibronectin

- Desmoglein

- M etastasis 
metastases (7). Cells from individual tumors exhibit differences with respect to cell surface constituents, immunogenicity, growth rates, karyotype, sensitivity to cytotoxic drugs, as well as their ability to invade and metastasize. Heterogeneity is not restricted to cells in primary tumors, being also prominent among metastatic cells (8).

Metastasis is the result of a complex series of events, such as loss of intercellular adhesion, entry of tumor cells into lymphatic and blood vessels, survival in the circulation and arrest at the target organ. Several mechanisms are implicated in the process, including changes in adhesion properties that allow tumor cell detachment and migration $(9,10)$. Adhesion of metastatic cells to the underlying extracellular matrix is very important (11), and the acquisition of metastatic competence by clones of cells with growth advantages is thought to be associated with an ability to coordinate the adhesive properties in every step of metastasis.

Lopes and colleagues (unpublished data) isolated a human colorectal cell line from a hepatic metastasis at the Ludwig Institute, São Paulo, SP, Brazil. This cell line (LISP-I) has been studied and compared to other established human colorectal cell lines $(4,12-$ 14) and has been shown to be resistant to growth stimulation by interleukins- 1 and -6 (4) as well as by insulin-like growth factorsI and -II or transforming growth factor- $\alpha$ (12). In parallel, this lineage was shown to be susceptible to natural killer cell-mediated lysis (14), which is considered to be the most important immune mechanism for the destruction of metastatic cells. Taken together, these data indicated that a better understanding of LISP-I biology would be a new option for studying the metastatic phenotype. The purpose of the present study was to investigate some behavioral aspects of LISP-I based on its heterogeneous morphology. In vitro growth rate, expression of two cell adhesion molecules, interaction with two extracellular matrix proteins and in vitro tumorigenic- ity were the parameters chosen for comparison between two morphologically distinct isolated cell populations within the LISP-I cell line.

\section{Material and Methods}

\section{Cell culture condition and cloning}

The LISP-I cell line was kindly provided by Dr. R. Brentani, Ludwig Institute for Cancer Research, São Paulo, SP, Brazil. Cells were grown in Dulbecco's modified Eagle's medium (DMEM, Gibco BRL, Grand Island, NY, USA) supplemented with $10 \%$ FCS (Cultilab, Campinas, SP, Brazil), 10 mM HEPES (Inlab, São Paulo, SP, Brazil) and $40 \mu \mathrm{g} / \mathrm{ml}$ gentamicin (Schering, São Paulo, SP, Brazil) at $37^{\circ} \mathrm{C}$ in a $5 \%$ humidified $\mathrm{CO}_{2}$ incubator until $80 \%$ confluence. Adherent cells were washed with PBS and detached by trypsinization $(0.2 \%$ trypsin0.02\% EDTA, Instituto Adolfo Lutz, São Paulo, SP, Brazil). To obtain single cellderived clones, cell suspensions were submitted to limiting dilution in 96-well culture plates (Costar, Cambridge, MA, USA).

\section{Growth rate determination}

Growth rate studies were carried out on single-cell suspensions derived from $\log$ phase cultures. LISP-A 10 or LISP-E1 1 cells were plated in duplicate $\left(10^{4}\right.$ and $\left.3 \times 10^{4}\right)$ in 24-well tissue culture plates. After $24 \mathrm{~h}$, attached cells were washed, removed by trypsinization and counted by vital die exclusion with $0.4 \%$ Trypan blue (Sigma Chemical Co., St. Louis, MO, USA). Counts were performed every $24 \mathrm{~h}$ until day 6 and population doubling rates were calculated from exponential growth curves.

\section{Flow cytometry}

LISP-A10 and LISP-E11 were analyzed for cell surface expression of desmoglein 
and carcinoembryonic antigen (CEA) as follows. Cells were harvested by trypsinization as described, fixed with $1 \%$ paraformaldehyde in PBS, washed and incubated for $1 \mathrm{~h}$ in the presence of $10 \mu \mathrm{g} / \mathrm{ml}$ anti-desmoglein mAb (Boehringer-Mannheim Corp., Mannheim, Germany), $60 \mu \mathrm{g} / \mathrm{ml}$ anti-CEA mAb (15) or $60 \mu \mathrm{g} / \mathrm{ml}$ unrelated antibody (preimmune mouse $\mathrm{IgG}$ ) at room temperature. After washing with $1 \%$ BSA (Inlab) in PBS, cells were resuspended in $200 \mu \mathrm{l}$ of 1:50 ( $\mathrm{v} /$ v) FITC-goat anti-mouse IgG (Sigma) in PBS and incubated for $45 \mathrm{~min}$ at room temperature. Cells were washed twice with $1 \%$ BSA $(w / v)$ in PBS, resuspended in $500 \mu 1$ PBS and analyzed with a FACScan apparatus (Becton Dickinson, San Jose, CA, USA). Dead cells were excluded based on forward and side scatter.

\section{Adhesion assays}

The laminin 1-nidogen complex from mouse Engelbreth-Holm-Swarm tumor was a gift from Dr. V.R. Martins, Ludwig Institute for Cancer Research. Fibronectin was affinity-purified from fresh human plasma as described elsewhere (16). Adhesion assays were performed in triplicate according to a classical protocol, with modifications (17). Briefly, 96-well culture plates (Costar) were coated with laminin or fibronectin at different concentrations, but in the same molar ratio, for $2 \mathrm{~h}$ at $37^{\circ} \mathrm{C}$. Wells were blocked with $1 \%$ BSA in PBS for $1 \mathrm{~h}$ at $37^{\circ} \mathrm{C}$ and washed with PBS. Cells (5 x 104) were suspended in serum-free medium (DMEM) and added to each coated well. After the end of the incubation period $\left(3 \mathrm{~h}\right.$ at $\left.37^{\circ} \mathrm{C}\right)$, nonadherent cells were washed off by flushing with PBS three times. Remaining adhered cells were fixed with $100 \%$ methanol for $5 \mathrm{~min}$, washed three times with PBS and stained with $0.2 \%$ crystal violet in $2 \%$ ethanol for $5 \mathrm{~min}$. Wells were exhaustively washed with PBS and the absorbed stain was dissolved in $50 \%$ ethanol in a $0.1-\mathrm{M}$ sodium citrate solution. Absorbance was measured at $550 \mathrm{~nm}$.

\section{Migration assays}

Migration assays were performed according to Jasiulionis et al. (18), with minor modifications. The outer membrane of Transwell ${ }^{\circledR}$ chambers (Costar) with $8-\mu \mathrm{m}$ diameter pores was coated with $10 \mu \mathrm{g} / \mathrm{ml}$ of laminin or fibronectin for $2 \mathrm{~h}$ at $37^{\circ} \mathrm{C}$, washed with PBS, quenched with $1 \%$ BSA in PBS for $1 \mathrm{~h}$ at $37^{\circ} \mathrm{C}$ and washed again. Cells $(2 \mathrm{x}$ $10^{5}$ ) were suspended in serum-free medium and added to each of the inner wells of the chamber. Cells were allowed to migrate for $16 \mathrm{~h}$ at $37^{\circ} \mathrm{C}$ in a $5 \%$ humidified $\mathrm{CO}_{2}$ incubator. Chambers were then gently washed three times with PBS and cells were fixed with $100 \%$ methanol for $5 \mathrm{~min}$. After washing with water, chambers were stained with $1 \%$ toluidine blue (Merck, São Paulo, SP, Brazil) in $1 \%$ sodium tetraborate (Sigma) and the remaining cells in the inner compartment were removed by scraping with a cotton swab. The absorbed stain present on membranes was suspended in 1\% SDS by incubation for $30 \mathrm{~min}$ at $37^{\circ} \mathrm{C}$, and optical density was read at $570 \mathrm{~nm}$. All experiments were performed in duplicate. Results were submitted to statistical analysis by comparing migration towards each protein with migration towards the negative control by the Student $t$-test.

\section{Anchorage-independent growth}

Anchorage-independent growth was assayed by suspending $5 \times 10^{5}$ cells of both cell clones in $0.6 \%$ agarose (Gibco BRL, Gaithersburg, MD, USA) over a $1 \%$ agarose base in 6well culture plates (Costar). Agarose was made up with DMEM supplemented with $10 \%$ FBS. Following gellification, additional medium was overlaid on the agarose and the plates were refed every 7 days (19). Colonies were grown until multicell spheroids could be observed. 


\section{Results}

\section{LISP-I subcloning and growth rate curves}

The highly heterogeneous cell line LISPI was cloned and two morphologically distinct subpopulations were obtained, as shown in Figure 1. The cell clone named LISP-A10 displays an epithelial-like intrapopulational organization, whereas LISP-E11 is a fibroblastoid, with sparse intercellular contacts. After several passages in culture, subpopulations were compared for in vitro growth rates. Figure 2 shows that LISP-A10 duplicated within $38.3 \mathrm{~h}$ while LISP-E11 duplicated within $30.4 \mathrm{~h}$.

\section{Expression of cell adhesion molecules}

Once the subpopulations displayed dis-

Figure 1. Phase contrast images of monolayer cultures of the LISP-I cell line and its cell clones: LISP-I (A); LISP-A10 (B), and LISP-E11 (C). Bars: $50 \mu \mathrm{m}$.
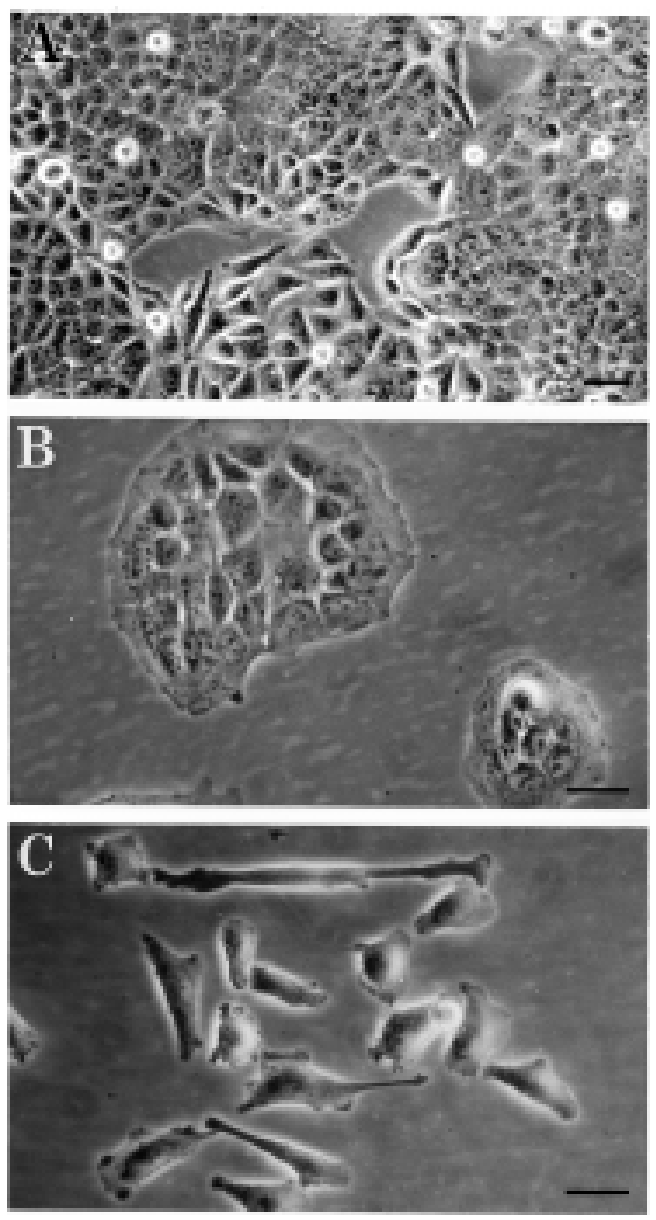

tinct cellular organization in monolayer cultures, the expression of two cell adhesion molecules, CEA and desmoglein, was investigated by indirect immunofluorescence with specific monoclonal antibodies, and analyzed by flow cytometry. Figure 3 demonstrates that both LISP-A 10 and LISP-E1 1 expressed CEA on their cell surfaces, while desmoglein was present only on LISP-A10.

\section{Interactions with extracellular matrix proteins}

Colorimetric adhesion assays were employed to evaluate the ability of LISP-A10 and LISP-E1 1 cells to adhere to laminin and fibronectin. Figure 4 shows that both subpopulations adhered to the two proteins in a dose-dependent manner with a tendency to saturation.

When LISP-A10 and LISP-E11 subpopulations were tested for their specific migration towards the two extracellular matrix components, both lineages were found to be able to migrate. Statistical analysis confirmed the specificity of migration of the two cell populations. Figure 5 shows that larger numbers of fibroblastoid cells LISP-E1 1 migrated more rapidly than LISP-A 10 towards immobilized laminin or fibronectin.

\section{Anchorage-independent growth}

To investigate in vitro tumorigenicity, LISP-A 10 and LISP-E11 were grown in soft agar cultures and Figure 6 shows that LISPA10 cells formed spheroid-like structures, while LISP-E11 did not, despite their anchorage-free survival.

\section{Discussion}

The colorectal carcinoma cell line LISPI is highly heterogeneous, presenting cell populations with different morphologies. Considering that this diversity may have contributed to the metastatic event, the aim of 
the present study was to isolate different LISP-I subpopulations and to investigate some of their behavioral patterns. After cell cloning, the sublineages chosen for comparison displayed distinct morphology patterns, as shown in Figure 1. The epithelial-like population LISP-A10 indicates a more differentiated phenotype when compared to the fibroblastoid clone LISP-E11.

One of the first noticeable different characteristics of the cell clones was their growth in culture, with the fibroblastoid cell clone LISP-E11 duplicating its cell number within a shorter period of time than the LISP-A 10 clone (Figure 2). The proliferation rates of cell populations are usually an indication of differentiation status, since poorly differentiated cell lines often proliferate faster than differentiated ones.

Biological heterogeneity is a common feature found among different tumors and, despite the monoclonal origin of most neoplasias, represents the major barrier to the treatment of cancer metastasis (7). The tumor mass contains several cell clones differing in morphology, growth rate and metastatic potential. Genetic and epigenetic mechanisms underlie this heterogeneity (6).

Fewer than one in ten thousand cells from the primary tumor are able to survive in the circulation, which makes metastasization a relatively rare event (20). It is thus considered a result of a selective process, in which heterogeneity could confer adaptive advantages to the tumor mass that escaped from its original organ $(21,22)$.

Multiple sequential steps are required to enable a malignant cell to establish metastases at a distant site (23). As the first step, a tumor cell must be released from the primary tumor by loss of cell-cell adhesion. Intercellular contact is mediated mainly by adhesion molecules that include members of the immunoglobulin, cadherin, integrin, selectin and proteoglycan superfamilies (24). Cellcell adhesion can also play a major role in the transduction of transmembrane signals, regulating cell differentiation, motility and fate. Thus, interactions among cells result in structural and regulatory functions (25).

CEA belongs to the immunoglobulin superfamily and is a widely known tumor marker that has been shown to play a role as a homotypic intercellular adhesion molecule $(26,27)$. Also, CEA has been implicated in the development of hepatic metastases from colorectal cancers $(23,28)$. It has been shown that poorly metastatic human colon cancer cell lines become highly metastatic when transfected with the cDNA coding for CEA by a mechanism not yet fully understood (29). To verify whether the epithelial morphotype of LISP-A10 was associated with higher CEA expression, immunodetection by flow cytometry was performed. Indeed,

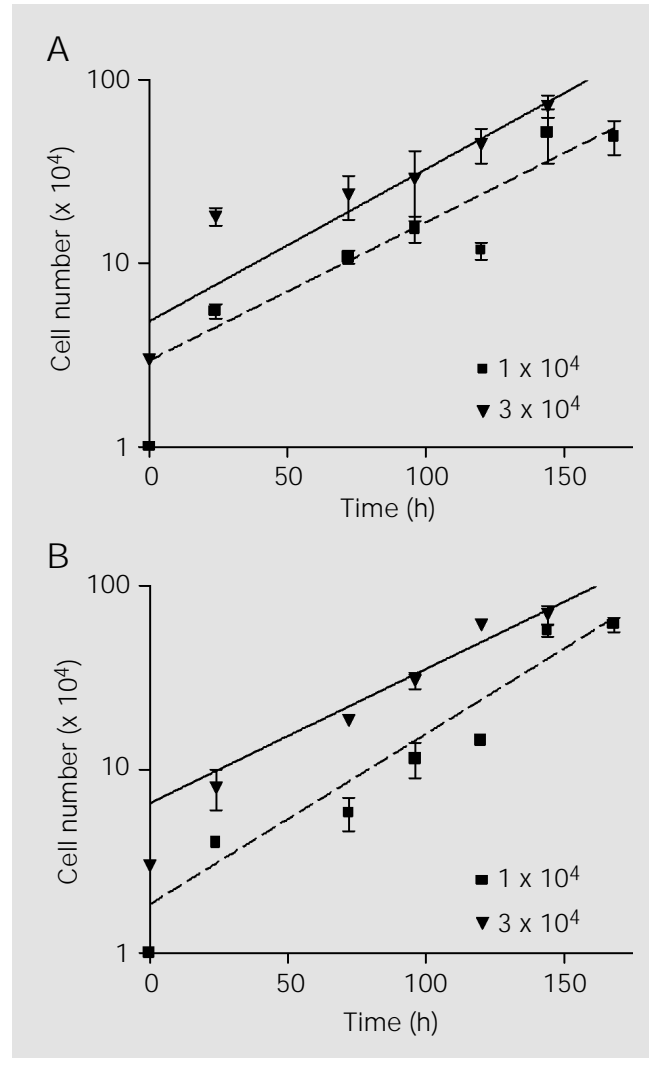

Figure 2. Growth curves of LISP-A10 (A) and LISP-E11 (B) clones. Cells $\left(1 \times 10^{4}\right.$ or $\left.3 \times 10^{4}\right)$ were plated on day 0 and growth curves were generated by counting viable cells every $24 \mathrm{~h}$ in $24-w e l l$ culture plates. Population growth rates were calculated from these curves. 

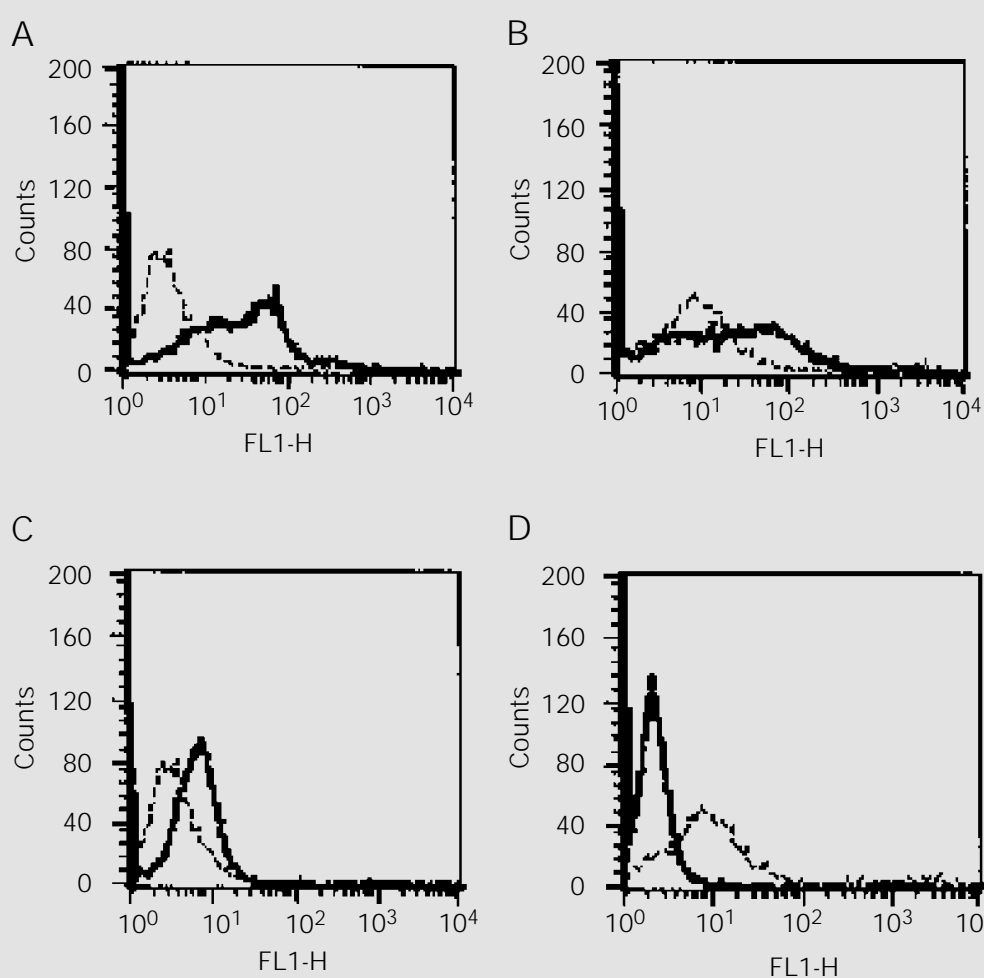

D

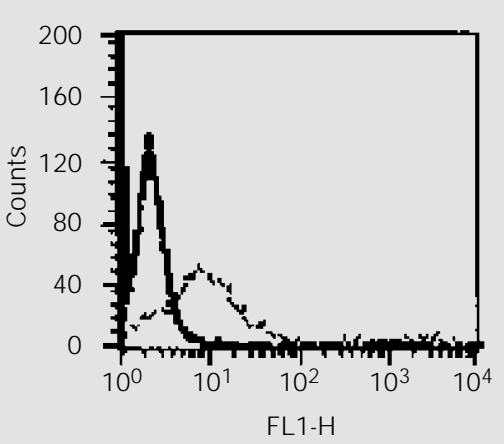

Figure 3. Carcinoembryonic antigen ( $A$ and $B$ ) and desmoglein ( $C$ and $D$ ) expression on the cell surface of the two clones, analyzed by flow cytometry using specific antibodies (solid lines). LISP-A10 (A and C), LISP-E11 (B and D). Dashed lines represent the negative control (normal mouse purified IgG). FL1-H: fluorescence intensity.

Figure 4. Adhesion of $5 \times 10^{4}$ cells from LISP-A10 (A) and LISP-E11 (B) cell clones in response to increasing concentrations of laminin, fibronectin or $1 \%$ BSA (control) adsorbed to the solid phase. The graphs show a representative result from four experiments. Error bars indicate the standard deviation.

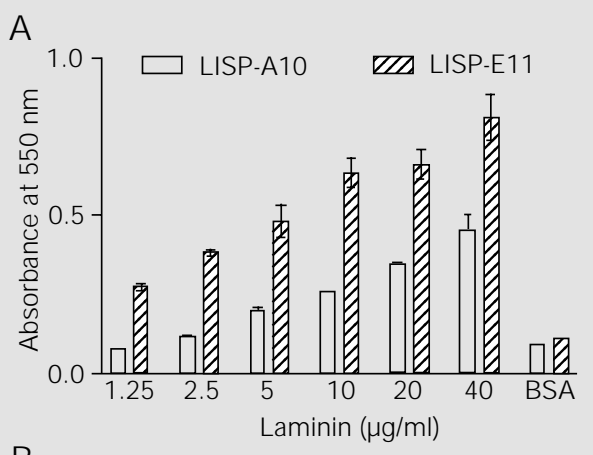

B

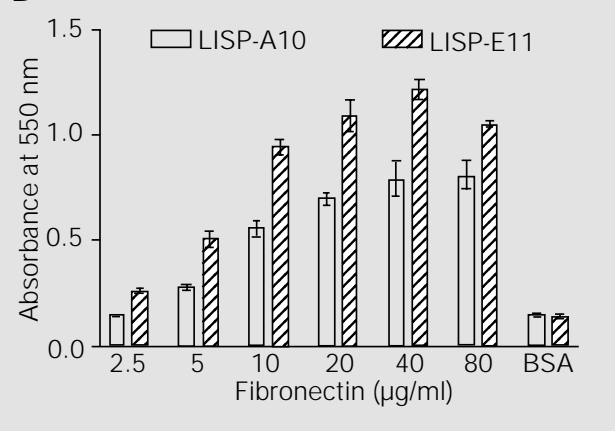

LISP-A 10 expresses higher amounts of CEA on its cell surface than LISP-E11 (Figure 3A and B).

The other intercellular adhesion molecule studied was desmoglein, an important cadherin superfamily member, which is essential for cell-cell adhesion since it is one of the main components of desmosomes (30, 31). Again, it was observed that the epithelial morphotype LISP-A10 produces desmoglein, while LISP-E11 does not (Figure 3C and $\mathrm{D})$. It has been proposed that the morphological characteristics of tumors (32) as well as CEA expression $(14,29)$ are directly related to their degree of differentiation. Based on the present observations concerning in vitro morphology and expression of intercellular adhesion molecules, it may be suggested that LISP-A10 displays a more differentiated phenotype than LISP-E11.

Another important step in the metastatic process is the interaction of tumor cells with the surrounding extracellular matrix. In this study, the adhesive properties of LISP-A10 and LISP-E11 to laminin and fibronectin were analyzed by colorimetric adhesion assays (Figure 4). Both cell populations adhered to these extracellular matrix components, although LISP-A 10 adhered to a lesser extent. This finding could be explained by the formation of aggregates by cells from this population, thus reducing cell surface availability to interact with proteins in the solid phase. Correlating the adhesion behavior to the degree of differentiation, Daneker Jr. and colleagues (32) found similar differences, with poorly differentiated colorectal carcinoma cell clones adhering better to laminin and fibronectin than a well-differentiated one. Interestingly, LISP-E11, which is poorly differentiated, readily spread on fibronectin, but not on laminin, after contact with these proteins (data not shown). This finding is in accordance with another report that showed spreading of poorly differentiated tumor cells on extracellular matrix components (32). A possible explanation for this 
observation is that the LISP-E11 cell clone has been adaptively selected for its ability to rapidly recognize, adhere to and spread on fibronectin, which is present in the space of Disse in the liver. The space of Disse contains a discontinuous extracellular matrix composed of collagen types I and IV and fibronectin, but not laminin (23). However, laminin is present in the basement membranes of the endothelium of central and portal veins. One may speculate that the tumor cell mass that reached the liver adhered to laminin on the basement membrane, degraded it and migrated on the digested matrix to the space of Disse. Then, there would be a switch of the enzyme specificity resulting in the activation of fibronectinspecific enzymes. This hypothetical switch would have been the result of a selective pressure on cells that conquered the new environment of the secondary metastatic site. If so, all these phenomena would have facilitated the metastatic event that originated the LISP-I cell line.

Even if they can attach to and degrade extracellular matrix, tumor cells will still fail to complete the invasion process if they are unable to migrate. Laminin and fibronectin can serve as substrata for cell attachment and spreading as well as a signal for cell migration. Active migration towards extracellular matrix components is one of the most important requirements for the success of metastasization (33) and can be analyzed by simple in vitro systems. However, depending on their concentration, extracellular matrix molecules may have opposite effects on cell migration (34). In the present report, colorimetric assays of migration were performed with an optimal protein concentration, based on previous results of adhesion assays. Thus, LISP-A10 and LISP-E11 subpopulations were compared for their locomotion ability. The fibroblastoid cell morphotype LISP-E1 1 was shown to migrate towards immobilized laminin or fibronectin, which is in accordance with its poorly differentiated pheno- type. On the other hand, LISP-A10 presented a discrete migration towards these proteins, as shown in Figure 5. This behavior could be explained by the strong aggregates formed by LISP-A 10 cells due to the expression of intercellular adhesion molecules, which prevent cell migration.

To investigate the anchorage-independent growth ability of both lineages, cells were grown in soft agar cultures. This assay is considered to be an in vitro method that correlates with in vivo tumorigenicity (35). Figure 6 demonstrates that LISP-A10 was able to form spheroid-like structures, while LISP-E1 1 was not, despite its survival. These observations indicate that both cell subpopu-
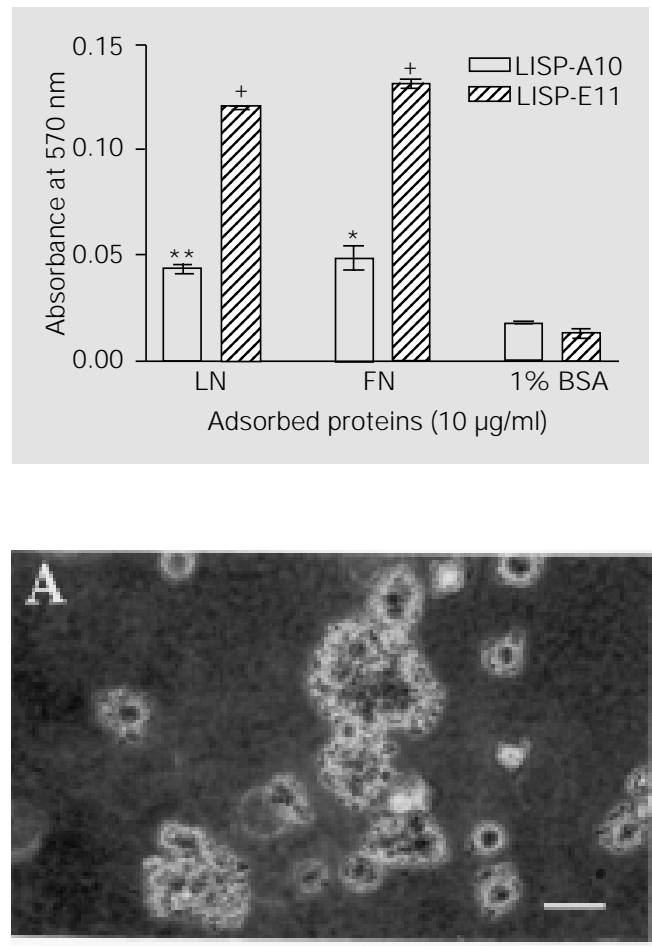

Figure 6. Anchorage-independent growth of LISP-A10 (A) and LISP-E11 (B). Known numbers of log-phase cells in single-cell suspensions were plated onto $0.6 \%$ agarose. Colonies were grown for 14 days and spheroid formation was noticed after 7 days, only for LISP-A10. Bars: 50 $\mu \mathrm{m}$.

Figure 5. Migration of LISP-A10 and LISP-E11 cell clones towards laminin (LN) and fibronectin (FN) in comparison to $1 \%$ BSA (control) immobilized on the outer surface of a modified Boyden served after 16 -h incubation at $37^{\circ} \mathrm{C}$. Experiments were performed in duplicate and analyzed by the Student t-test $(* P=0.03$; ** $\mathrm{P}=0.007$ and $+\mathrm{P}<0.001)$. The graph shows one representative experiment. Error bars indicate the standard deviation.

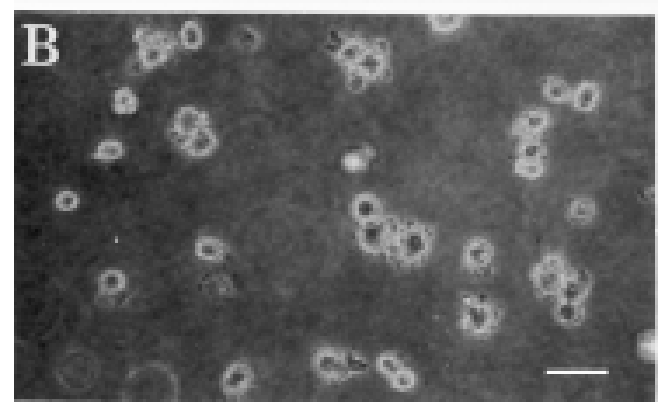


lations present a malignant phenotype. Interestingly, recent data have shown that the two clones maintain their proliferation after nearly one month in this condition with no medium replacement (Carneiro CRW and Guariniello LD, unpublished results), suggesting the secretion of an autocrine growth factor. This finding is under investigation in our laboratory.

In the present study we identified two morphologically distinct subpopulations within the LISP-I cell line. Morphological differences were shown to correlate with diverse functional properties that probably contributed to the metastasis from which the LISP-I cell line was isolated. Thus, the het- erogeneity displayed by the LISP-I cell line may have been a positive selected feature, with LISP-A10 contributing to the maintenance of cell aggregates in the circulation, and LISP-E11, with its migration ability, contributing to the invasive steps of metastasization. The cell sublineages herein reported represent new models that may be used to address biological questions concerning tumorigenesis and metastasization.

\section{Acknowledgments}

The authors wish to thank Dr. Miriam Galvonas Jasiulionis for help with the flow cytometry assays.

\section{References}

1. Winawer SJ (1999). Natural history of colorectal cancer. American J ournal of Medicine, 106: 3S-6S.

2. Ministério da Saúde (1999). Estimativa da Incidência e Mortalidade por Câncer no Brasil. INCa, Rio de J aneiro.

3. Trainer DL, Kline T, McCabe FL, Faucette LF, Field J , Chaikin M, Anzano M, Rieman D, Hoffstein S, Li D-J , Gennaro D, Buscarino C, Lynch $M$, Poste $G \&$ Greig $R$ (1988). Biological characterization and oncogene expression in human colorectal carcinoma cell lines. International J ournal of Cancer, 41: 287-296.

4. Lahm H, Petral-Malec P, Yilmaz-Ceyhan A, Fischer J R, Lorenzoni M, Givel J -C \& Odartchenko N (1992). Growth stimulation of a human colorectal carcinoma cell line by interleukin- 1 and -6 and antagonistic effects of transforming growth factor $B_{1}$. European J ournal of Cancer, 28A: 1894-1899.

5. Lahm H, Amstad P, Yilmaz A, Borbenyi Z, Wyniger J , Fischer J R, Suardet L, Givel J C \& Odartchenko N (1995). Interleukin 4 down-regulates expression of c-kit and autocrine stem cell factor in human colorectal carcinoma cells. Cell Growth and Differentiation, 6: 1111-1118.

6. Brentani R (1989). The molecular basis of the metastatic phenotype. Critical Reviews in Oncogenesis, 1: 247-260.

7. Singh RK, Tsan R \& Radinsky R (1997). Influence of the host microenvironment on the clonal selection of human colon carcinoma cells during primary tumor growth and metastasis. Clinical and Experimental Metastasis, 15: 140-150.

8. Fidler IJ (1985). Macrophages and metastasis - a biological approach to cancer therapy: presidential address. Cancer Research, 45: 4714-4726.

9. Liotta LA \& Kohn E (1990). Cancer invasion and metastasis. J ournal of the American Medical Association, 263: 1123-1126.

10. Yoong KF, Afford SC, Randhawa S, Hubscher SG \& Adams DH (1999). Fas/ Fas ligand interaction in human colorectal hepatic metastases: a mechanism of hepatocyte destruction to facilitate local tumor invasion. American J ournal of Pathology, 154: 693-703.

11. Haier J, Nasralla M \& Nicolson GL (1999). Different adhesion properties of high and poorly metastatic HT-29 colon carcinoma cells with extracellular matrix components: role of integrin expression and cytoskeletal components. British J ournal of Cancer, 80: 1867-1874.

12. Lahm $H$, Suardet $L$, Laurent $P L$, Fischer J R, Ceyhan A, Givel J -C \& Odartchenko N (1992). Growth regulation and co-stimulation of human colorectal cancer cell lines by insulin-like growth-factor I, II and transforming growth factor $\alpha$. British J ournal of Cancer, 65: 341-346.

13. Lahm H, Amstad P, Wyniger J , Yilmaz A, Fischer J R, Schreyer M \& Givel J C (1994). Blockade of the insulin-like growth-factorI receptor inhibits growth of human colo- rectal cancer cells: evidence of a functional IGF-II-mediated autocrine loop. International J ournal of Cancer, 58: 452459.

14. Prado IB, Laudanna AA \& Carneiro CRW (1995). Susceptibility of colorectal-carcinoma cells to natural-killer-mediated lysis: Relationship to CEA expression and degree of differentiation. International J ournal of Cancer, 61: 854-860.

15. Carneiro CRW, Lopes J D \& Brentani MM (1987). Carcinoembryonic antigen (CEA): production of immunoprecipitating monoclonal antibodies and development of an enzyme immunoassay. Hybridoma, 6: 689-692.

16. Akiyama SK \& Yamada KM (1985). The interaction of plasma fibronectin with fibroblastic cells in suspension. J ournal of Biological Chemistry, 260: 4492-4500.

17. Taraboletti G, Belotti D, Giavazzi R, Sobel ME \& Castronovo V (1993). Enhancement of metastatic potential of murine and human melanoma cells by laminin receptor peptide G: attachment of cancer cells to subendothelial matrix as a pathway for hematogenous metastasis. J ournal of the National Cancer Institute, 85: 235-240.

18. J asiulionis MG, Chammas R, Ventura AM, Travassos LR \& Brentani RR (1996). Alpha6 betal-integrin, a major cell surface carrier of beta1-6-branched oligosaccharides, mediates migration of EJ -ras-transformed fibroblasts on laminin-1 independently of its glycosylation state. Cancer Re- 
search, 56: 1682-1689.

19. Sacks PG, Parnes SM, Gallick GE, Mansouri Z, Lichtner R, Satya-Prakash KL, Pathak S \& Parsons DF (1988). Establishment and characterization of two new squamous cell carcinoma cell lines derived from tumors of the head and neck. Cancer Research, 48: 2858-2866.

20. Liotta LA (1992). Cancer cell invasion and metastasis. Scientific American, 266: 3441.

21. Morikawa K, Walker SM, Nakajima M, Pathak S, J essup J M \& Fidler IJ (1988). Influence of organ environment on the growth, selection, and metastasis of human colon carcinoma cells in nude mice. Cancer Research, 48: 6863-6871.

22. BreivikJ \& Gaudernack G (1999). Carcinogenesis and natural selection: A new perspective to the genetics and epigenetics of colorectal cancer. Advances in Cancer Research, 76: 187-211.

23. J essup J M \& Thomas P (1989). Carcinoembryonic antigen: function in metastasis by human colorectal carcinoma. Cancer and Metastasis Reviews, 8: 263-280.

24. Gumbiner BM (1996). Cell adhesion: The molecular basis of tissue architecture and morphogenesis. Cell, 84: 345-357.
25. Ben-Ze'ev A (1997). Cytoskeletal and adhesion proteins as tumor suppressors. Current Opinion in Cell Biology, 9: 99108.

26. Benchimol S, Fucks A, J othy S, Beauchemin N, Shirota K \& Stanners CP (1989). Carcinoembryonic antigen, a human tumor marker, functions as an intercellular adhesion molecule. Cell, 57: 327-334.

27. Chakrabarty S, Rajagopal S \& Moskal TL (1998). Protein kinase C $\alpha$ controls the adhesion but not the antiproliferative response of human colon carcinoma cells to transforming growth factor ß1: identification of two distinct branches of post-protein kinase $\mathrm{C} \alpha$ adhesion signal pathway. Laboratory Investigation, 78: 413-421.

28. Hostetter RB, Augustus LB, Mankarious $R$, Chi K, Fan D, Toth CA, Thomas $P \&$ J essup J M (1990). Carcinoembryonic antigen as a selective enhancer of colorectal cancer metastases. J ournal of the National Cancer Institute, 82: 380-385.

29. Gangopadhyay A, Bajenova O, Kelly TM \& Thomas P (1996). Carcinoembryonic antigen induces cytokine expression in Kupffer cells: implications for hepatic metastasis from colorectal cancer. Cancer Research, 56: 4805-4810.
30. Garrod DR (1993). Desmosomes and hemidesmosomes. Current Opinion in Cell Biology, 5: 30-40.

31. Smith EA \& Fuchs E (1998). Defining the interactions between intermediate filaments and desmosomes. J ournal of Cell Biology, 141: 1229-1241.

32. Daneker J r GW, Piazza AJ , Steele J r GD \& Mercurio AM (1989). Relationship between extracellular matrix interactions and degree of differentiation in human colon carcinoma cell lines. Cancer Research, 49: 681-686.

33. Grimstad IA (1987). Direct evidence that cancer cell locomotion contributes importantly to invasion. Experimental Cell Research, 173: 515-523.

34. Coopman PJ , Bracke ME, Lissitzky J C, de Bruyne GK, van Roy FM, Foidart J M \& Mareel MM (1991). Influence of basement membrane molecules on directional migration of human breast cell lines in vitro. J ournal of Cell Science, 98: 395401.

35. Ruoslahti E (1999). Fibronectin and its integrin receptors in cancer. Advances in Cancer Research, 76: 1-20. 